\title{
SIMULTANEOUS SPECTROPHOTOMETRIC DETERMINATION OF Cu(II) AND Co(II) USING 5-BROMOSALICYLALDEHYDE THIOSEMICARBAZONE BY PARTIAL LEAST SQUARES REGRESSION METHOD
}

\author{
Le Ngoc Tu${ }^{1}$, Le Van Tan ${ }^{2, *}$ and Nguyen Xuan Chien ${ }^{3}$ \\ ${ }^{1}$ Ho Chi Minh City University of Education, Ho Chi Minh City 700000, Vietnam \\ ${ }^{2}$ Department of Chemical Engineering, Industrial University of Ho Chi Minh City 700000, \\ Vietnam \\ ${ }^{3}$ Institute for Technology of Radioactive and Rare Elements, VAEI, Vietnam \\ *E-mail : levantan@iuh.edu.vn
}

\begin{abstract}
The simultaneous spectrophotometric method is described for the determination of $\mathrm{Cu}$ (II) and $\mathrm{Co}$ (II) by 5bromosalicylaldehyde thiosemicarbazone (5-BSAT) using partial least squares regression method. The ligand reacts with two ions to form greenish yellow and brown colored [Cu(II)-5-BSAT] and [Co(II)-(5-BSAT) $\left.)_{2}\right]$ complexes, respectively. The absorption peaks of these complexes were found overlapping at $\lambda \max$ of $378 \mathrm{~nm}$ and $381 \mathrm{~nm}$, respectively. Formation of all of these complexes was complete within $20 \mathrm{~min}$ at $\mathrm{pH} 5.0$. The linear ranges were $4.0 \times 10^{-6} \mathrm{M}-9.6 \times 10^{-6} \mathrm{M}$ for $\mathrm{Cu}(\mathrm{II})$ and $8.0 \times 10-6 \mathrm{M}-8.0 \times 10-5 \mathrm{M}$ for $\mathrm{Co}$ (II) with molar absorptivity, $\varepsilon$ of $1.09 \times 10^{4}$ L.mol ${ }^{-1} \cdot \mathrm{cm}^{-1}$ and $1.42 \times 10^{4} \mathrm{~L} \cdot \mathrm{mol}^{-1} \cdot \mathrm{cm}^{-1}$, respectively. Partial least squares (PLS) regression method is proposed for the simultaneous determination of these ions with the spectrophotometric absorbance data between wavelengths 370 and $446 \mathrm{~nm}$ at an interval of $4 \mathrm{~nm}$. A training set was generated and its accuracy was tested in a test set. The test set garnered a root mean square error (RMSE) of 0.192 for copper and 0.489 for cobalt. The relatively small RMSE suggests only a small difference between predicted versus measured concentrations, demonstrating the accuracy of our model. The proposed method is successfully employed in the analysis of water sample for determining concentrations of copper and cobalt.
\end{abstract}

Keywords: partial least squares (PLS), 5-bromosalicylaldehyde thiosemicarbazone, simultaneous determination, spectrophotometry.

(C) RASĀYAN. All rights reserved

\section{INTRODUCTION}

Copper and cobalt appear together in many real samples. Cobalt is obtained from copper ore as a byproduct. Both metals are essential trace elements for plants and animals. Cobalt is a key constituent of vitamin B-12 and uses for the formation of alloys. Copper is also combined with other metals to make alloys. It is a good electrical conductor and has a diverse role in oxygen transport system.

Several techniques such as atomic absorption spectrometry (AAS), X-ray fluorescence spectrometry, inductively coupled plasma-optical emission spectrometry (ICP-OES), inductively coupled plasma mass spectrometry (ICP-MS), voltammetry, high-performance liquid chromatography (HPLC) etc. have been used for the simultaneous determination of these ions in different samples. Among these methods, the most widely used analytical methods are those based on the UV-Vis spectrophotometric techniques due to the resulting experimental rapidity, simplicity and the wide application. However, the simultaneous determination of these ions by the use of the traditional spectrophotometric techniques is difficult due to the high spectral overlapping observed in the absorbance spectra of their complexes. Recently, quantitative spectrophotometry has been greatly improved by the use of a variety of multivariate statistical methods such as classical least square (CLS), inverse least square (ILS), principal component regression (PCR), and partial least squares (PLS). Multivariate calibrations are effective in the 
spectrophotometric analysis because the simultaneous inclusion of multiple spectral intensities can greatly improve the precision and applicability. The widespread use of these methods is due to the proliferation of commercial software for laboratory computers and detectors capable of recording full spectra very rapidly. ${ }^{1}$

Thiosemicarbazones are a group of compounds obtained by condensing thiosemicarbazide with carbonyl compounds in the presence of a few drops of glacial acetic acid. These reagents function as good chelating agents and form complexes with several metal ions by bonding through thionate sulphur atom and hydrazine nitrogen atom. However, when there is a hydroxyl group in the ortho position in compounds such as salicylaldehyde thiosemicarbazone, 5-bromosalicylaldehyde thiosemicarbazone, ohydroxyacetophenonethiosemicarbazone etc, they behave as tridentate ligands and form a bond through an oxygen atom in ortho hydroxyl group. The wide use of thiosemicarbazones in the inorganic analysis has been reviewed in detail by Suparupu et al, Grag and Jain, Grag and Sing usually using spectrophotometric technique. ${ }^{2-11}$ Few reports have been published on the simultaneous determination of $\mathrm{Cu}$ (II) and $\mathrm{Co}$ (II) in different samples. ${ }^{12-14}$ Until now, there is no scientific paper in the application of 5-bromosalicylaldehyde thiosemicarbazone (5-BSAM) for simultaneous determination of these ions. In the present work a very rapid, sensitive, selective and low-cost PLS for simultaneous determination of copper and cobalt using 5-BSAT in dimethylformamide (DMF) solvent is described. The method has been successfully applied for simultaneous determination of copper and cobalt in synthetic water samples.

\section{Chemicals}

\section{EXPERIMENTAL}

All chemical used were of analytical reagent grade of Merck chemical companies. Doubly distilled water was used throughout.

Stock solutions of $\mathrm{Cu}(\mathrm{II})$ and $\mathrm{Co}(\mathrm{II})(0.01 \mathrm{M})$ were prepared from a suitable mass of those compounds and made up to the mark in a 100-ml volumetric flask. Working standard solutions of these ions were prepared by appropriate dilution of the stock solution.

Buffer solutions were prepared from a suitable amount of acetic acid and sodium acetate.

A $0.01 \mathrm{M}$ reagent solution was prepared by dissolving $0.0685 \mathrm{~g}$ of 5-BSAT in $25 \mathrm{ml}$ DMF. Working solution of reagent was prepared by diluting the stock in DMF solution to an appropriate volume.

\section{Apparatus and Software}

A Perkin - Elmer Lambda 25 QA - Certificate spectrophotometer was used to record the absorbance spectra with a $1 \mathrm{~cm}$ quartz cuvette was utilized for absorbance studies. Mettler Toledo digital $\mathrm{pH}$ meter with a combined glass electrode was used for $\mathrm{pH}$ measurements.

The programs used to obtain and process the spectra were supplied by the spectrophotometer manufacturer as bundled software. PLS were carried out using the R for Windows package version 3.3.3. ${ }^{15-16}$

\section{Procedure}

Known amounts of the standard solutions of each cation, $5.0 \mathrm{ml}$ of buffer solution and $2.5 \mathrm{ml}$ of DMF solution were placed in a $25 \mathrm{ml}$ volumetric flask and completed to final volume with deionized water (final $\mathrm{pH}$ was 5.0). The final concentration of these solutions varied between $0-9.6 \times 10^{-5} \mathrm{M}$ and $0-8.0 \times 10^{-5}$ $\mathrm{M}$ for copper and cobalt, respectively. Finally, the spectra of all prepared solutions were recorded on a spectrophotometer.

\section{Introduction to PLS Algorithm}

The initial data were preprocessed by autoscaling using the PLS package under the Program R. ${ }^{16}$ The PLS algorithm was utilized for the development of our calibration models. Partial least squares is a powerful multivariate statistical technique that has been successfully applied in many areas. Details of the technique can be referred to in Otto. ${ }^{17}$ Briefly, it involves the decomposition of A (absorbance matrix) and $\mathrm{C}$ (concentration matrix) as follows: 


$$
\begin{aligned}
& \mathrm{A}=\mathrm{TP}^{\mathrm{T}}+\mathrm{E} \\
& \mathrm{C}=\mathrm{UQ}^{\mathrm{T}}+\mathrm{F}
\end{aligned}
$$

Where $\mathrm{T}$ and $\mathrm{U}$ are the nxd scores matrices containing orthogonal rows; $\mathrm{P}$ comprises the pxd loadings of the A matrix; $\mathrm{E}$ is the nxp error (residual) of A matrix; $\mathrm{Q}$ is the mxd loadings of the $\mathrm{C}$ matrix; and $\mathrm{F}$ is the nxm error (residual) of the $\mathrm{C}$ matrix. Computation of the B-coefficients is then given by the general model:

$$
\mathrm{B}=\mathrm{W}\left(\mathrm{P}^{\mathrm{T}} \mathrm{W}\right)^{-1} \mathrm{Q}^{\mathrm{T}}
$$

A cross-validation method was used to determine the number of PLS components to be used in the final model. This method performs the calibration on the data set minus one sample and predicts the concentration of the sample that was not included. Each of the samples is left out during the algorithm. Their concentrations are predicted and then compared to the actual concentrations. The root means square error of calibration (RMSEC) was determined for various numbers of components to calculate the optimum number to include in the model. The minimum RMSEC for the PLS model is 2 principal components using 20 wavelengths.

\section{Absorption Spectra}

\section{RESULTS AND DISCUSSION}

The absorption spectra for $\mathrm{Cu}(\mathrm{II})$ and $\mathrm{Co}(\mathrm{II})$ complexes with 5-BSAT against blank solution at $\mathrm{pH} 5.0$ in the wavelength range $370-500 \mathrm{~nm}$ are shown in Fig.-1. The maximum wavelengths of two complexes are $395 \mathrm{~nm}$ and $405 \mathrm{~nm}$, respectively. As shown in Fig.-1, the absorption spectra of the complexes overlap with each other and cannot be well resolved by the traditional procedures using simple calibrations. Therefore, each metal ion interferes in the spectrophotometric determination of the other. But the simultaneous determination of $\mathrm{Cu}(\mathrm{II})$ and $\mathrm{Co}(\mathrm{II})$ is possible by using PLS.

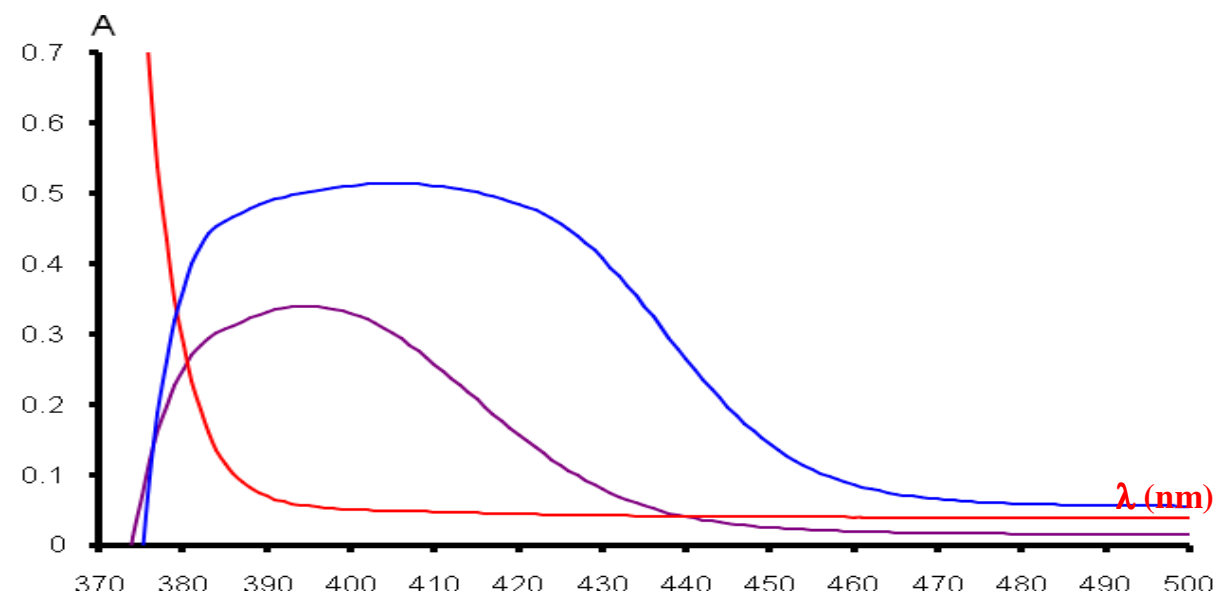

Fig.-1: Absorption Spectra of 5-BSAT Reagent (Red Curve), Cu-5-BSAT and Co-5-BSAT Complexes (Violet and Blue Curve, respectively) at $\mathrm{pH} 5.0$

\section{Determination of the Composition of Complexes}

The composition of complexes was determined by molar ratio method. From Fig.-2 and Fig.-3, we could conclude a 1:1 composition for $\mathrm{Cu}$ (II) complex and a 1:2 for $\mathrm{Co}(\mathrm{II})$ complex.

\section{Optimization of Various Parameters}

To take full advantage of the procedure, the reagent concentrations and reaction conditions must be optimized. These parameters were optimized by setting all parameters to be constant and optimizing one each time. 


\section{Effect of $\mathbf{p H}$}

The effect of $\mathrm{pH}$ on the spectra of a constant concentration of each complex was investigated in the range of 3.0-9.0. The results showed that two complexes exhibit maximum absorbance in the pH range 5.0- 6.0. For both cations, pH 5.0 was selected as the suitable one for simultaneous analysis of $\mathrm{Cu}$ (II) and $\mathrm{Co}$ (II).

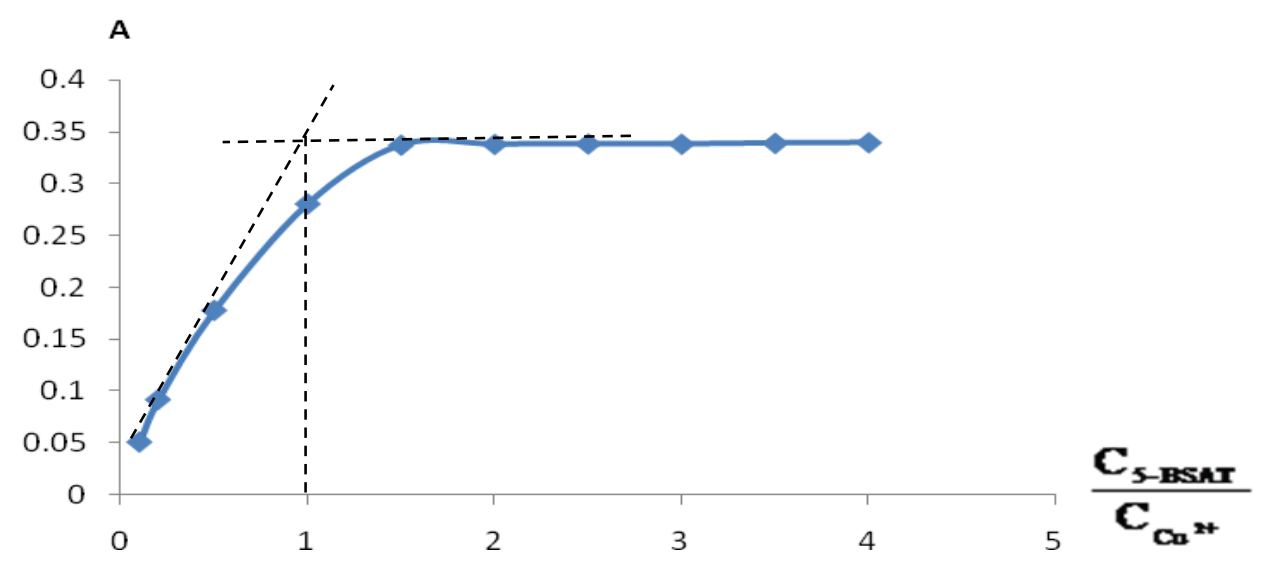

Fig.-2: Determination of Mole Ratio of Cu(II) - 5-BSAT Complex by Molar Ratio Method

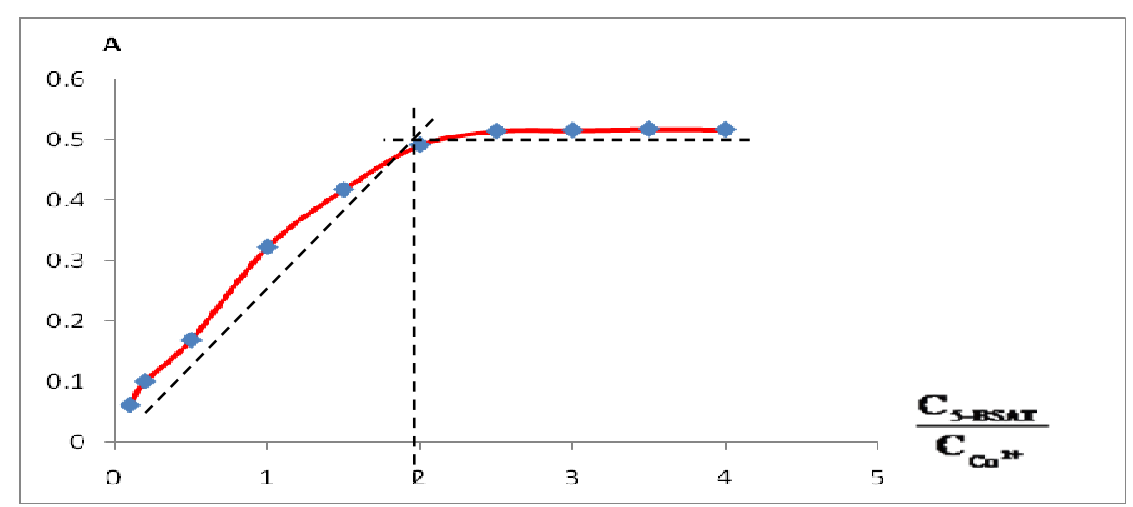

Fig.-3: Determination of Mole Ratio of Co(II) - 5-BSAT Complex by Molar Ratio Method

\section{Effect of Reagent Concentration}

Effect of different amounts of 5-BSAT on the absorbance of $\mathrm{Cu}$ (II)-5-BSAT and Co(II)-5-BSAT complexes was studied. It was expected that increasing reagent concentration causes an increase in absorbance because the increase in reagent concentration caused an increase in the concentration of $\mathrm{Cu}(\mathrm{II})$ and $\mathrm{Co}(\mathrm{II})$ complexes. At higher concentrations of 5-BSAT, the concentration of complexes did not change significantly but the concentration of uncomplexed 5-BSAT increased significantly. The results showed that, $1.6 \times 10^{-4} \mathrm{~mol} \mathrm{~L}^{-1}$ 5-BSAT, the fourfold excess over maximum concentration of metallic ions, was sufficient to get maximum complex formation.

\section{Time Effect}

To measure completeness of complex formation reaction, the absorbance values of these complexes were monitored at different intervals of time. For both $\mathrm{Cu}^{2+}$ and $\mathrm{Co}^{2+}$ ions, complex formation was completed after $20 \mathrm{~min}$ and stable for $60 \mathrm{~min}$. Therefore, further studies have been carried out at the range 20 - 60 min after mixing of reagents.

\section{Individual Calibration Curves}

The calibration curves obtained show a linear relationship between the distances measured and the concentrations of the metal ions in the range $4.0 \times 10^{-6}-9.6 \times 10^{-5}$ mol. $\mathrm{L}^{-1}$ of copper(II) and $8.0 \times 10^{-6}-$ 
$8.0 \times 10^{-5}$ mol. $\mathrm{L}^{-1}$ of cobalt(II); the corresponding correlation coefficients are 0.998 and 0.995 . The molar absorptivities, $\varepsilon$ of two complexes were $1.09 \times 10^{4}$ and $1.42 \times 10^{4} \mathrm{~L} \cdot \mathrm{mol}^{-1} \cdot \mathrm{cm}^{-1}$, respectively.

\section{Effect of Foreign Ions}

The effect of various foreign ions on the absorbance of a solution containing $2.0 \times 10^{-5}$ mol. $\mathrm{L}^{-1}$ each of $\mathrm{Co}(\mathrm{II})$ and $\mathrm{Cu}(\mathrm{II})$ was studied. An ion was considered to interfere when its presence produced a variation in the absorbance of the sample greater than 5\%. Table-1 summarizes the maximum tolerances of the investigated cations. Among the cations, $\mathrm{Ca}^{2+}, \mathrm{Mg}^{2+}, \mathrm{Al}^{3+}$ interfered a little, but $\mathrm{Ni}^{2+}$, $\mathrm{Cr}^{3+}, \mathrm{Fe}^{3+}$ ions interfered strongly to complexation of $\mathrm{Cu}^{2+}$ and $\mathrm{Co}^{2+}$ with 5-BSAT.

Table-1: Effect of Foreign Ions on the Determination of $2 \times 10^{-5} \mathrm{M}$ of $\mathrm{Cu}(\mathrm{II})$ and $\mathrm{Co}(\mathrm{II})$

\section{Analytical Application}

\begin{tabular}{c|c|c|c|c|c|c|c|c}
\hline Ion & $\mathrm{Ni}^{2+}$ & $\mathrm{Fe}^{3+}$ & $\mathrm{Zn}^{2+}$ & $\mathrm{Pb}^{2+}$ & $\mathrm{Ca}^{2+}$ & $\mathrm{Mg}^{2+}$ & $\mathrm{Al}^{3+}$ & $\mathrm{Cr}^{3+}$ \\
\hline $\mathrm{C} \times 10^{5}(\mathrm{M})$ & 24 & 36 & very large & very large & 400 & 316 & 250 & 20 \\
\hline
\end{tabular}

Two sets of standard solutions were prepared. The calibration set contains 11 standard solutions. The concentration of each cation solution was in the linear dynamic range of the cation, for the preparation of each solution, different volumes of two cation solutions $(0.01 \mathrm{M})$ were added to $5.0 \mathrm{ml}$ 5-BSAT solution $(\mathrm{pH}=5.0)$ in a $25 \mathrm{ml}$ volumetric flask. The generated mixture designs were then randomly divided into $70 \%-30 \%$ training $(\mathrm{n}=8)$ and testing sets $(\mathrm{n}=3)$, respectively. We developed calibration model using the training set and compared the performance of PLS technique in the independent test set using various R packages. All calculations were performed using R version 3.3.3. ${ }^{15-16}$ Evaluation of the performance of the chemometric technique was done using root mean square error (RMSE) (eqN. 4). The general equation is:

$$
R M S E=\sqrt{\frac{\sum_{i=1}^{N}\left(y_{i}-y_{i}^{\prime}\right)^{2}}{N}}
$$

Where $\mathrm{y}$ and $\mathrm{y}^{\prime}$ are the predicted and actual concentrations and $\mathrm{N}$ is the number of samples.

Table-2: Mixture Designs used for the Batch Standards $\left(\times 10^{6} \mathrm{M}\right)$

\begin{tabular}{c|c|c|c|c|c|c|c|c|c|c|c}
\hline Mixture & $\mathrm{M}_{1}$ & $\mathrm{M}_{2}$ & $\mathrm{M}_{3}$ & $\mathrm{M}_{4}$ & $\mathrm{M}_{5}$ & $\mathrm{M}_{6}$ & $\mathrm{M}_{7}$ & $\mathrm{M}_{8}$ & $\mathrm{~N}_{1}$ & $\mathrm{~N}_{2}$ & $\mathrm{~N}_{3}$ \\
\hline Copper & 4 & 4 & 4 & 5 & 8 & 10 & 10 & 12 & 6 & 6 & 10 \\
\hline Cobalt & 6 & 8 & 12 & 6 & 8 & 5 & 3 & 3 & 8 & 12 & 8 \\
\hline
\end{tabular}

After 30 minutes, absorption spectra of the mixtures recorded. The calibration matrix used for the analysis is shown in Table-2.

\section{Selection of Optimum Number of Components}

In this work, in order to select the number of significant PLS components, for modeling the system without overfitting the concentration data, a cross-validation method, leaving out one sample at a time, was used. Given the set of calibration spectra, the PLS calibration was performed, and using this calibration the concentration of the compounds in the sample left out during calibration was predicted. The predicted concentration of the compounds in each sample was compared with the known concentration of the compound in this reference sample and root means square error of prediction (RMSEP) was calculated. The maximum number of factors used to calculate the optimum RMSEP was selected 7. One reasonable choice for the optimum number of factors would be that number which yielded the minimum RMSEP. The calibration set used is the spectra of 8 samples taking absorbance data at 20 wavelengths with $4 \mathrm{~nm}$ intervals around between $370 \mathrm{~nm}$ and $446 \mathrm{~nm}$.

The RMSEP value is minimum in the number of 2 for both copper and cobalt, then the number of components is selected as optimum for the calibration model. In Figure 4, the RMSEP obtained by optimizing the calibration matrix of the absorbance data with PLS method is shown. The result is expressed in Table-3, which shows errors of predictions are low. 
RASĀYAN J. Chem.

Vol. 11 | No. 2 |850 - 856 | April - June | 2018
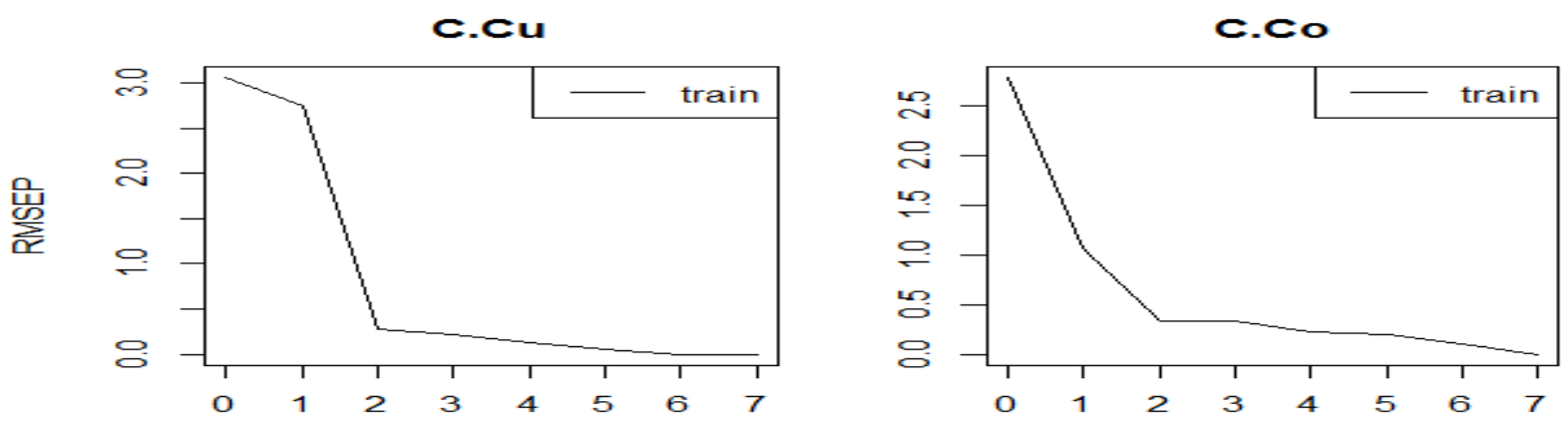

number of components

Fig.-4: Determination of Optimum Number of Components

Table-3: Prediction of Training Set Samples

\begin{tabular}{c|l|c|c|c}
\hline \multicolumn{2}{c|}{ Mixture } & $\mathrm{C}_{\text {added }} \times 10^{6}(\mathrm{M})$ & $\mathrm{C}_{\text {found }} \times 10^{6}(\mathrm{M})$ & Recovery (\%) \\
\hline \multirow{2}{*}{$\mathrm{M}_{1}$} & $\mathrm{Cu}^{2+}$ & 4 & 3.879 & 96.98 \\
\cline { 2 - 5 } & $\mathrm{Co}^{2+}$ & 6 & 5.563 & 92.72 \\
\hline \multirow{2}{*}{$\mathrm{M}_{2}$} & $\mathrm{Cu}^{2+}$ & 4 & 3.908 & 97.70 \\
\cline { 2 - 5 } & $\mathrm{Co}^{2+}$ & 8 & 8.214 & 102.68 \\
\hline \multirow{2}{*}{$\mathrm{M}_{3}$} & $\mathrm{Cu}^{2+}$ & 4 & 4.178 & 104.45 \\
\cline { 2 - 5 } & $\mathrm{Co}^{2+}$ & 12 & 11.688 & 97.40 \\
\hline \multirow{2}{*}{$\mathrm{M}_{4}$} & $\mathrm{Cu}^{2+}$ & 5 & 5.418 & 108.36 \\
\cline { 2 - 5 } & $\mathrm{Co}^{2+}$ & 6 & 6.679 & 111.32 \\
\hline \multirow{2}{*}{$\mathrm{M}_{5}$} & $\mathrm{Cu}^{2+}$ & 8 & 7.706 & 96.33 \\
\cline { 2 - 5 } & $\mathrm{Co}^{2+}$ & 8 & 7.940 & 99.25 \\
\hline \multirow{2}{*}{$\mathrm{M}_{6}$} & $\mathrm{Cu}^{2+}$ & 10 & 9.621 & 96.21 \\
\cline { 2 - 5 } & $\mathrm{Co}^{2+}$ & 5 & 5.207 & 104.14 \\
\hline \multirow{2}{*}{$\mathrm{M}_{7}$} & $\mathrm{Cu}^{2+}$ & 10 & 9.937 & 99.37 \\
\cline { 2 - 5 } & $\mathrm{Co}^{2+}$ & 3 & 2.772 & 92.40 \\
\hline \multirow{2}{*}{$\mathrm{M}_{8}$} & $\mathrm{Cu}^{2+}$ & 12 & 12.353 & 102.94 \\
\cline { 2 - 5 } & $\mathrm{Co}^{2+}$ & 3 & 2.937 & 97.90 \\
\hline \multirow{2}{*}{} & & &
\end{tabular}

The results obtained by applying PLS algorithm to the three test set samples are listed in Table- 4 . The test set had a root mean square error (RMSEP) of 0.192 for copper and 0.489 for cobalt. The relatively small RMSEPs again verify the good performance of PLS model in predicting the concentrations of cations in mixture solutions.

Table-4: Prediction of Test Set Samples

\begin{tabular}{c|l|c|c|c}
\hline \multicolumn{2}{l|}{ Mixture } & $\mathrm{C}_{\text {added }} \times 10^{6}(\mathrm{M})$ & $\mathrm{C}_{\text {found }} \times 10^{6}(\mathrm{M})$ & Recovery (\%) \\
\hline \multirow{2}{*}{$\mathrm{N}_{1}$} & $\mathrm{Cu}^{2+}$ & 6 & 5.747 & 95.78 \\
\cline { 2 - 5 } & $\mathrm{Co}^{2+}$ & 8 & 8.010 & 100.13 \\
\hline \multirow{2}{*}{$\mathrm{N}_{2}$} & $\mathrm{Cu}^{2+}$ & 8 & 7.830 & 97.88 \\
\cline { 2 - 5 } & $\mathrm{Co}^{2+}$ & 12 & 11.978 & 99.82 \\
\hline \multirow{2}{*}{$\mathrm{N}_{3}$} & $\mathrm{Cu}^{2+}$ & 10 & 10.132 & 101.32 \\
\cline { 2 - 5 } & $\mathrm{Co}^{2+}$ & 8 & 8.840 & 110.50 \\
\hline
\end{tabular}

CONCLUSION

The copper-cobalt mixture is an extremely difficult complex system due to the high spectral overlapping observed between the absorption spectra for these components. Simultaneous determination of mixtures of $\mathrm{Cu}$ (II) and $\mathrm{Co}$ (II) directly was performed by spectrophotometric measurements using 5bromosalicylaldehyde thiosemicarbazone as an analytical reagent, and chemometric modeling. Results showed that the PLS is a rapid and efficient method for simultaneous determination of mixtures of $\mathrm{Cu}$ (II) 
and Co(II) in a water sample. The high analytical potential of the PLS created satisfactory results. The method offers the good procedure for the analyzing of complex mixtures, using a simple spectrophotometer, which is available in most laboratories and without the need of preconcentration or extraction steps. Thus, the inherent errors involved in these time-consuming steps using toxic and carcinogenic organic solvents are avoided and determination in the aqueous phase makes the procedure eco-friendly.

\section{REFERENCES}

1. Parixit Rohitbhai Prajapati1, Deepika Natu Rathod, Vishalkumar Shashikant Modi, Tarashankar Basuri, International Journal of Pharmaceutical Chemistry and Analysis, 3(1), 43(2016), DOI: 10.5958/2394-2797.2016.00005.8.

2. Lakshmi Narayana Suvarapu, Adinarayana Reddy Somala, Janardhan Reddy Koduru, Sung Ok Baek and Varada Reddy Ammireddy, Asian Journal of Chemistry, 24(5), 1889(2012).

3. Tarlok S. Lobana, Rekha Sharma, Gagandeep Bawa, Sonia Khanna, Coordination Chemistry Reviews, 253, 977(2009), DOI: 10.1016/j.ccr.2008.07.004.

4. J.S. Casas, M.S. García-Tasende, J. Sordo, Coordination Chemistry Reviews, 209, 197(2000), DOI: 10.1016/S0010-8545(00)00363-5.

5. Subhash Padhye and George B.Kauffman, Coordination Chemistry Reviews, 63, 127(1985), DOI: 10.1016/0010-8545(85)80022-9.

6. B. S. Garg and V. K. Jain, Microchemical Journal, 38, 144(1988), DOI: 10.1016/0026265X(88)90017-3.

7. R. B. Singh, B. S. Garg and R. P. Sinch, Talanta, 25, 619(1978), DOI: 10.1016/00399140(78)80163-5.

8. Ramanjaneyulu G., Raveendra Reddy P., Krishna Reddy V., Sreenivasulu Reddy T., Indian Journal of Chemistry. Sect. A: Inorganic Physical, Theoretical \& Analytical, 41(7), 1436(2002).

9. Ramanjaneyulu G., Raveendra Reddy P., Krishna Reddy V., Sreenivasulu Reddy T, Journal of the Indian Chemical Society, 80(8), 773(2003).

10. Ramanjaneyulu G., Raveendra Reddy P., Krishna Reddy V., Sreenivasulu Reddy T, The Open Analytical Chemistry Journal, 2, 78(2008), DOI: 10.2174/1874065000802010078.

11. Le Van Tan, Le Ngoc Tu, Nguyen Xuan Chien, European Chemical Bulletin, 2(6), 311(2013), DOI: 10.17628/ecb.2013.2.311-314.

12. Adela Bermejo-Barrera, Pilar Bermejo-Barrera and F. Bermejo Martinez, Analyst, 11, 1313(1985), DOI: 10.1039/AN9851001313.

13. J. M. Castro-Romero, J. M. Fernandez-Solis, Ma. H. Bollain-Rodriguez, F. Bermejo-Martinez, Microchemical Journal, 43(2), 104(1991), DOI: 10.1016/0026-265X(91)90003-8.

14. Chao Lu, Jin-Ming Lin, Carmen W. Huie, Masaaki Yamada, Analytical Science, 19, 557(2003), DOI: 10.2116/analsci.19.557.

15. R for Windows (2017). Available from: https://www.r-project.org/.

16. Ron Wehrens, Chemometrics with R: Multivariate Data Analysis in the Natural Sciences and Life Sciences $1^{\text {st }}$ Edition, Springer (2011).

17. M. Otto, Chemometrics: Statistics and Computer Application in Analytical Chemistry $3^{\text {rd }}$ Edition, Wiley (2017).

[RJC-2088/2018] 